\title{
"O espaço da literatura em sala de aula": Diferentes abordagens do trabalho com o texto literário na Educação Básica
}

\section{"The space of literature in the classroom": Different approaches of the literary text in Basic Education}

\author{
Amalia Cardona Leites ${ }^{1}$ \\ Alyssa Dillenburg Michalski ${ }^{2}$ \\ Juliana de Andrade Missio ${ }^{3}$
}

\begin{abstract}
Resumo
A constante formação de professores de Língua Portuguesa da Educação Básica no que diz respeito às múltiplas abordagens do texto literário é fundamental para que estes profissionais possam pautar sua atuação por estratégias eficazes no processo de ensino-aprendizagem. $O$ objetivo deste relato de experiência é apresentar a ação de extensão "O espaço da literatura na sala de aula", ocorrida no segundo semestre de 2020 no âmbito do Instituto Federal do Rio Grande do Sul (IFRS). Sabemos que não basta à escola apresentar diferentes discursos e possibilitar o contato com diversas manifestações artísticas para que o aluno desenvolva seu letramento crítico. O papel da leitura literária no espaço escolar deve ir além da fruição estética e do entretenimento, buscando explorar diferentes tipos de textos, superar barreiras de leitura e ir além do senso comum. Ao discutir a multiplicidade de abordagens do estudo do texto literário em sala de aula na rede básica, esta ação fomentou um rico debate entre participantes de todo o país. Foi possível perceber que existe uma carência em discussões desta área, e que futuras ações semelhantes seriam extremamente favoráveis tanto para os docentes quanto para os graduandos (e futuros docentes) da área de Letras.
\end{abstract}

Palavras-chave: Letramento literário. Literatura. Formação de professores.

\begin{abstract}
The constant training of Portuguese language teachers of Basic Education regarding the multiple approaches of the literary text is fundamental for these professionals to be able to guide their action through efficient strategies in the teaching-learning process. The aim of this experience report is to present the extension action "The space of literature in the classroom", occurred in the second trimester of 2020 in the scope of the Instituto Federal do Rio Grande do Sul (IFRS). We know that it is not enough for the school to present different discourses and enable the contact with diverse artistic manifestations for the student to develop their critical literacy. The role of literary reading in the school extent must go beyond aesthetical delight and entertainment, looking forward to exploring different kinds of texts, to overcoming reading barriers and to going beyond the common sense. By discussing the multiplicity of approaches to the study of literary text in the basic network classroom, this action promoted a rich debate among participants from all over the country. It was possible to notice that there is a lack of discussions of this area, and that future similar actions would be extremely favourable for both teachers and for undergraduates (and future teachers) of the Letters field.
\end{abstract}

Keywords: Literary literacy. Literature. Education of teachers.

\section{Introdução}

\footnotetext{
${ }^{1}$ Doutora em Letras. Instituto Federal Catarinense - Campus Ibirama, Santa Catarina, Brasil. Orcid: https://orcid.org/00000002-7790-736X. E-mail: amalia.leites@ifc.edu.br

${ }^{2}$ Estudante de Ensino Médio Técnico. Instituto Federal do Rio Grande do Sul - Campus Bento Gonçalves, Rio Grande do Sul, Brasil. Orcid: https://orcid.org/0000-0002-0885-7637. E-mail: alyssadillenburgm@gmail.com

${ }^{3}$ Estudante de Ensino Médio Técnico. Instituto Federal do Rio Grande do Sul - Campus Bento Gonçalves, Rio Grande do Sul, Brasil. Orcid: https://orcid.org/0000-0001-5047-6259. E-mail: julianadeandrademissio@gmail.com
}

LínguaTec, Instituto Federal de Educação, Ciência e Tecnologia do Rio Grande do Sul, Bento Gonçalves v. 6 , n. 2, p. 143-152, nov. 2021 
Apesar da educação brasileira ter avançado muito no que diz respeito ao número de pessoas alfabetizadas, ainda sofremos as consequências de uma sociedade cujos jovens são pouco letrados 4 . Diversos pesquisadores da área da Educação têm se debruçado sobre quais seriam os novos desafios colocados aos docentes em um momento no qual a tecnologia facilita o acesso a uma imensa quantidade de textos, porém a capacidade de compreensão destes textos tem se mostrado deficitária. Assim, qualificar a atuação dos graduandos de Letras e dos professores de Língua Portuguesa tanto do Ensino Fundamental quanto do Ensino Médio é fundamental para que estes profissionais possam pautar sua atuação por estratégias eficazes no processo de ensino-aprendizagem.

É possivvel perceber que muitos docentes e graduandos no exercício de sua profissão encontram dificuldades em construir práticas pedagógicas que tenham a literatura no seu centro - ao invés de ser mero pretexto para o trabalho com gêneros textuais ou gramática, por exemplo. Da mesma forma, observamos que pode ser um desafio encontrar obras que despertem o interesse dos alunos ao mesmo tempo em que contribuam para a ampliação de seu repertório cultural. A tentativa de funcionar como uma possível resposta a estas inquietações foi que motivou a organização do ciclo de palestras "O espaço da literatura em sala de aula", realizado pelo projeto de extensão Conversas Literárias, do Instituto Federal do Rio Grande do Sul (IFRS). O evento teve a finalidade de estabelecer um diálogo entre a teoria e a prática docente no que diz respeito ao espaço da leitura literária e da literatura nas aulas de Língua Portuguesa da Educação Básica em todos os seus níveis, por meio da discussão de vários aspectos que atravessam o fazer docente e da diversidade de seus palestrantes. Os docentes convidados examinaram o tema sob diferentes perspectivas: desde reflexões teóricas até relatos de experiência, passando pelas especificidades da literatura afro-brasileira e indígena. Buscando estimular uma reflexão sobre o papel do professor de Língua Portuguesa em sala de aula e sobre as possibilidades e desafios do trabalho com o texto literário, o ciclo de palestras também atuou no sentido da formação e qualificação de professores graduandos de Letras e professores de Língua Portuguesa de diferentes regiões do país.

\section{Fundamentação teórica}

A despeito de limitações e críticas que podem (e devem) ser feitas, os documentos norteadores da educação pública brasileira (Lei de Diretrizes e Bases-LDB, Parâmetros Curriculares Nacionais do

\footnotetext{
${ }^{4}$ Esclarecemos aqui que entendemos o conceito de "letramento" como o resultado da ação de ler e escrever em um contexto de linguagem como prática social, segundo explica Roxane Rojo (2017).
} 
Ensino Médio- PCNEM e Orientações Curriculares Nacionais do Ensino Médio - OCNEM) concordam entre si quanto à questão da importância de que o estudante aprimore sua autonomia intelectual e seu conhecimento sobre as manifestações artísticas e literárias que constituem o patrimônio cultural do país. Também é definida nestes documentos, na área específica de Linguagens, a necessidade de que se trabalhe a habilidade de relacionar discursos tanto com sua condição de produção quanto com o contexto sócio-histórico de sua circulação:

Os produtos culturais das diversas áreas (literatura, artes plásticas, música, dança etc.) mantêm intensa relação com seu tempo. 0 aluno deve saber, portanto, identificar obras com determinados períodos, percebendo-as como típicas de seu tempo ou antecipatórias de novas tendências. Para isso, é preciso exercitar o reconhecimento de elementos que identificam e singularizam tais obras [...] (PCNEM+, 2000, p. 65)

Algumas questões já se apresentam ao lermos este trecho dos PCNEM+: Como pode 0 estudante reconhecer os elementos que singularizam as diferentes obras artísticas contemporâneas se muitas vezes nem o próprio docente teve ou tem acesso a tais obras? Sabemos que a difusão de manifestações artísticas não-hegemônicas é bastante limitada em nosso país, e que sua circulação também é restrita. Por outro lado, a ampliação da presença das classes populares nas escolas públicas de ensino médio e superior trouxe para a escola novos discursos, novas formas de se compreender e de se fazer arte, e pode ocorrer deste contato entre práticas letradas valorizadas e não-valorizadas ser relativamente conflituoso, se não for adequadamente mediado.

É neste sentido que Roxane Rojo aponta para a necessidade da circulação de discursos plurais por intermédio de práticas sociais de multiletramentos no espaço escolar, estabelecendo uma relação direta com a promoção do letramento crítico:

\footnotetext{
Um dos objetivos principais da escola é justamente possibilitar que seus alunos possam participar das várias práticas sociais que se utilizam da leitura e da escrita (letramento) na vida da cidade, de maneira ética, crítica e democrática [...]. Será necessário ampliar e democratizar tanto as práticas e eventos de letramentos que têm lugar na escola como o universo e a natureza dos textos que nela circulam. (ROJO, 2017, p. 107-108)
}

Entretanto, sabemos que não basta à escola apresentar diferentes discursos e possibilitar o contato com variadas manifestações artísticas para que o aluno desenvolva seu letramento crítico. 0 papel da leitura literária no espaço escolar deve ir além da fruição estética e do entretenimento e, para tanto, o papel do professor é crucial. A aula de literatura precisa ser o espaço no qual o aluno aprende a explorar diferentes tipos de textos, a superar barreiras de leitura, a ir além do senso comum para atribuir 
sentido às atividades de linguagem que ele participa em determinados contextos sociais de comunicação e interação humana. Da mesma forma, Rildo Cosson argumenta que lemos literatura da maneira como fomos ensinados a ler, e que

[...] nossa capacidade de leitura depende, em grande parte, desse modo de ensinar, daquilo que nossa sociedade acredita ser objeto de leitura e assim por diante. A leitura simples é apenas a forma mais determinada de leitura, porque esconde sob a aparência de simplicidade todas as implicações contidas no ato de ler e de ser letrado. É justamente para ir além da simples leitura que o letramento literário é fundamental no processo educativo. (COSSON, 2016, p. 29-30, grifo nosso)

Aqui, mostra-se válido ponderar quais as manifestações literárias que, no Brasil de hoje, nas escolas e universidades, são ensinadas como sendo legítimas e suficientes para se tornarem objetos de leitura nas aulas de literatura. Sabemos que a lista é bastante extensa e que nunca há tempo suficiente para "cumprir o programa". À vista disso, assim como iniciamos esta seção mencionando documentos oficiais que tratam da educação, nos valemos agora de outra legislação para tentar contribuir com este questionamento: a Lei 10.639, promulgada em 2003, que tornou obrigatório o ensino da história e cultura afro-brasileira e africana nas escolas; e a lei 11.645, de 2008, que incluiu no currículo oficial da rede de ensino a obrigatoriedade da temática indígena.

Segundo essas leis, todas as escolas de ensino fundamental e médio, públicas e privadas, devem ter incluído em seus currículos (especialmente nas áreas de educação artística, literatura e história) o estudo da história da África, dos africanos e dos indígenas, com suas lutas e culturas. Essa inclusão deve ter como objetivo valorizar positivamente e enfatizar a contribuição destes grupos - nas áreas social, econômica e política - para a formação da população brasileira.

Porém, mesmo que não sejam recentes, esses dispositivos têm enfrentado dificuldades ao serem implementados nas escolas e cursos de Letras de todo o país. A escritora e pesquisadora indígena Graça Graúna argumenta que, para além do que estabelece a lei 10.639, é preciso discutir também o método como ocorrem estes estudos:

O estudo da representação do negro e do índio na literatura requer uma abordagem específica. Da maneira como 0 assunto vem sendo trabalhado, sobretudo nas escolas dominantes, 0 processo de formação política, social, econômica e cultural imposto aos povos indígenas e africanos continuará sendo ignorado. A expressão artística do ameríndio e do africano sugere uma leitura das diferenças, pois 0 ato de conhecer 0 outro implica 0 ato de interiorizar a história, a auto-história, as nossas raízes. (GRAÚNA, 2013 p. 46-47)

O movimento de colocar em execução a legislação vigente não pode consistir somente na presença de meia dúzia de obras literárias de autoria negra ou indígena nas bibliotecas das escolas e 
universidades. Essa leitura das diferenças só é verdadeiramente efetivada quando há um compromisso maior com uma educação plural e crítica.

A professora Íris Amâncio ressalta que a leitura de textos de literaturas africanas de Língua Portuguesa e de literaturas afro-brasileiras pode contribuir para concretizar as intenções da Lei 10.639, afirmando que

Diante da necessidade de o Brasil minimizar o abismo secularmente estabelecido pelas consideráveis diferenças socioeconômicas de base racista, destaca-se, uma vez mais, a função do educador que, como professor, "compreende e assume que seu papel é de iniciar o sujeito em linguagens" [...]. (AMÂNCIO, 2014, p. 44)

Esse papel do professor como aquele que "inicia o sujeito em linguagens" é exatamente o que foi buscado ao longo das cinco semanas de atividades do Ciclo de Palestras aqui relatado. Além de trazermos para a discussão a literatura indígena e negro-brasileira, em uma tentativa de contribuir na formação dos participantes referente às Leis 10.639 e 11.645, foram apresentadas diferentes estratégias de ensino, com diferentes objetivos e metodologias, detalhados na próxima seção.

\section{Descrição da experiência}

As experiências vivenciadas durante o período de planejamento e execução do ciclo de palestras aqui relatado permitiram à equipe organizadora e aos participantes entrarem em contato com diversas faces da literatura, seu ensino e estudo, através da oportunidade de ouvir diferentes professoras e professores, pesquisadores e referências e interagir com pessoas de todo Brasil, possuidoras de diferentes formações.

Após a definição da programação, e como estratégia inicial de divulgação, foram mapeados grupos e páginas de Facebook que tivessem afinidade com a temática proposta: grupos/páginas de professores de inglês, português e literatura e grupos/páginas de estudantes de curso superior em Letras de diferentes instituições nas redes sociais. Em seguida, a fim de divulgar o evento, as duas bolsistas estudantes do $1^{0}$ ano do Ensino Médio Técnico na Instituição - criavam postagens e cards promocionais na plataforma on-line Canva. Esses cards seguiam dois caminhos - eram postados no Facebook e também enviados via WhatsApp com uma antecedência de aproximadamente quinze dias do evento, e novamente um dia antes de cada palestra. Ademais, os cards também eram postados nas redes sociais do projeto "Conversas Literárias", ao qual essa ação estava institucionalmente vinculada. 
As palestras foram transmitidas ao vivo pelo canal no Youtube oficial do Campus. As bolsistas administravam as mensagens mandadas no chat e disponibilizavam os formulários de presença e avaliação durante cada palestra. Estes formulários ficaram abertos até 0 final do ciclo. A primeira apresentação foi "Escola de Contadores de Histórias: o despertar do narrador", com o escritor, roteirista, diretor de teatro, professor e contador de história José Henrique Alves de Castilhos. Ocorreu no dia 27 de outubro de 2020 e durou uma hora e vinte minutos, período em que o palestrante compartilhou suas experiências como contador de histórias e explicou formas de trabalhar com a contação de histórias em sala de aula - especialmente com alunos mais novos - e como esta atividade pode despertar o interesse pela literatura em pessoas de diferentes idades. Até o mês de abril de 2021, ela havia tido mais de 400 visualizações.

Na sequência, na palestra "Literatura negro-brasileira em sala de aula: temas e abordagens" Silvani Lopes Lima, docente do Instituto Federal do Rio Grande do Sul (IFRS) Campus Ibirubá, discutiu a importância de uma educação antirracista e como ela pode ser promovida em aulas de literatura. Silvani também fez referências a diferentes obras literárias que permitem abordar a literatura negro-brasileira em sala de aula, para as diferentes séries e níveis. Esta palestra teve uma duração de uma hora e trinta minutos, e também teve quase 400 visualizações até a presente data.

Na semana seguinte, a escritora, ativista e pesquisadora da Universidade Estadual do Rio de Janeiro (UERJ), Fernanda Vieira, tratou o tema "Literaturas indígenas de mulheres: território do saber ancestral", e falou sobre a importância das literaturas indígenas, como e por que estudá-las, além de indicar métodos e leituras sobre o assunto. Vista por aproximadamente 300 pessoas, a transmissão teve uma hora e vinte minutos de duração. Logo depois, no dia 18 de novembro, Samira Dall Agnol, docente da Universidade Caxias do Sul (UCS), foi a responsável pela palestra "A leitura literária e a formação docente: experiências de leituras", com um período de uma hora e trinta minutos. Na atividade, que teve 250 visualizações, a palestrante discutiu suas experiências pessoais, a forma pela qual a literatura influenciou e moldou sua formação, a importância da leitura literária e o que é e como formar um leitor.

A quinta palestra foi mediada pela docente Andréia Kanitz, do IFRS Campus Bento Gonçalves, no dia 24 de novembro. Com o tema "Aula de literatura no $1^{\circ}$ ano do ensino médio: da leitura à produção textual", a convidada partiu de suas próprias experiências como estudante de Letras e professora de Língua Portuguesa para refletir acerca das dinâmicas da leitura literária em sala e como é possível, a partir da literatura, estimular a produção textual no Ensino Médio. A transmissão durou uma hora e trinta minutos e conta atualmente com mais de 300 visualizações.

O último dia do evento, em dezembro, contou com a presença de duas professoras de Língua Portuguesa e teve a duração de uma hora e trinta minutos, além de 200 visualizações. 0 primeiro tema 
foi apresentado por Natalia Gasparini, docente do IFRS Campus Restinga - "Slam: ideias para levar a batalha de poesia para a sala de aula". Nela, a palestrante explicou o que é slam e como ele pode ser trabalhado na sala de aula com adolescentes, além de apresentar diferentes slammers contemporâneos e a dinâmica das batalhas de poesia. Já a segunda palestra foi "A aula de literatura como espaço de descolonização do saber", apresentada por Michele Mafessoni, docente do IFRS Campus Bento Gonçalves. Nela, a palestrante discutiu conceitos como lugar de fala e descolonização, e promoveu uma reflexão sobre os processos de colonialidade, sugerindo diversas referências literárias que são tanto fontes de conhecimento quanto a representação de obras que promovem a descolonização do saber na aula de Língua Portuguesa.

Ao final de cada palestra, os participantes foram convidados a preencher um formulário disponível pelo Google Forms para registrar sua presença. Neste formulário havia também um campo para avaliação de cada uma das palestras, com perguntas de múltipla escolha e espaço aberto para comentários. Foram contabilizadas aquelas pessoas que obtiveram no mínimo $75 \%$ de presença, e estas receberam certificado. Mesmo com o término do evento, todas as transmissões estão disponíveis no canal do Campus no Youtube e podem ser encontradas em uma playlist. A menção ao tempo de duração e número de visualizações de cada palestra serve como referência para percebermos as particularidades e o imenso potencial que este tipo de atividade possui. Observamos que após a primeira hora da atividade virtual, a audiência começava a diminuir e, portanto, é preciso levar a questão do tempo em conta no momento em que se planejem outras atividades similares a esta. Apesar de também ter sido verificado que, com o passar das semanas, houve uma certa queda geral no número de participantes ao vivo, o fato de os vídeos permanecerem on-line e permitirem o acesso posterior garante a continuidade da divulgação das palestras.

\section{Avaliação dos resultados}

Para o ciclo de palestras foram recebidas 223 inscrições, sendo 59,7\% de estudantes e $36,9 \%$ de professores. Dentre as pessoas inscritas, 167 de fato assistiram a alguma palestra, sendo que um total de 68 receberam o certificado de 12 horas por terem atendido ao critério de mínimo de $75 \%$ de participação. A equipe de execução e os palestrantes, que somaram 10 pessoas, também foram certificados, completando um total de 78 certificados. No geral, as palestras foram avaliadas como ótimas $(85,8 \%)$ e boas (14,2\%); não houve nenhuma classificação negativa.

A primeira palestra, "Escola de contadores de histórias: o despertar do narrador", foi avaliada com ótima por $83,6 \%$ dos participantes, como relata o comentário de um participante: "Estou adorando 
a fala do José Henrique, pois ele tem o dom de prender a atenção e está nos informando muitas ideias maravilhosas. Amei o diálogo sobre o silêncio". (LUÍSA BEATRIZ RIBAR VAZ, professora)

Na segunda palestra, "Literatura negro-brasileira em sala de aula: temas e abordagens", também houve uma significativa participação, como mostra o comentário seguinte que, inclusive, menciona uma atividade desempenhada pela participante:

\begin{abstract}
"Estou gostando muito da fala da Silvani. Entendo que devemos ler e valorizar muito mais a literatura afrodescendente. Inclusive, neste momento de estudos remotos, os meus estudantes produziram a Contação de Contos Africanos através da produção de vídeos. Adoro estas trocas de leituras e experiências". (LUÍSA BEATRIZ RIBAR VAZ, professora.)
\end{abstract}

A palestra de Fernanda Vieira, "Literaturas indígenas de mulheres: território do saber ancestral", foi considerada ótima por $84,4 \%$ dos participantes, como destaca o seguinte comentário: "A palestra foi satisfatória, pois apresenta um nível de conhecimento que pode adequar a prática pedagógica dos professores em sala de aula". (VERONICA NEVES CARDOSO, professora.)

A quarta palestra, "A leitura literária e a formação docente: experiências de leituras", foi avaliada como ótima por $83,8 \%$ dos ouvintes, como enfatiza a observação: "Excelentes contribuições para nos tornar leitores de opiniões!". (VERONICA NEVES CARDOSO, professora.)

A quinta palestra foi a melhor avaliada entre as do ciclo, uma vez que $95,7 \%$ dos participantes consideraram-na ótima, como exemplifica o comentário: "Muito interessante a exposição sobre a experiência com o ensino de literatura. A reflexão é necessária para que a aprendizagem seja significativa. Obrigada pela oportunidade!". (ALCIONE PEREIRA SANTOS RODRIGUES FERREIRA, professora.)

As duas últimas palestras, "Slam: ideias para levar a batalha de poesia para a sala de aula" e "A aula de literatura como espaço de descolonização do saber", foram avaliadas juntas como 86,5\% ótimas e $13,5 \%$ boas, como destaca o comentário "A palestra contém um conteúdo motivador, é inspiradora em criar novos leitores reflexivos e participativos" (VERONICA NEVES CARDOSO, professora.)

O sucesso e impacto do ciclo de palestras foram ainda mais salientados pela seguinte observação, feita no último dia do evento:

"Participei de todos os encontros e adorei. Foram momentos de conversas muito dinâmicas e com diversas indicações de trabalhos escolares, de obras literárias e de atividades artísticas. Estou muito feliz por ter participado com vocês. Parabéns a todos os organizadores e, na noite de hoje, vocês finalizaram com "chave de ouro", porque 
os diálogos da Nathália e da Michele foram excelentes. Gratidão!". (LUÍSA BEATRIZ RIBAR VAZ, professora)

Cabe mencionar que, durante as palestras, houve inúmeras outras manifestações dos participantes. Através de perguntas ou comentários no chat, socializaram-se experiências docentes, dificuldades e sugestões de atividades para todos os níveis e séries. Assim, ainda que tenha ocorrido de maneira virtual, foi possível perceber o alcance legítimo das discussões promovidas.

\section{Considerações finais}

A reflexão sobre a teoria e prática docente em sala de aula foi inicialmente promovida pelas intervenções dos palestrantes, sendo logo ampliada pela presença das vozes dos demais participantes que, tanto através de comentários ou perguntas no chat quanto através de manifestações no formulário de avaliação, relataram suas próprias experiências docentes. Entendemos que 0 caráter da ação articulou as dimensões de ensino, pesquisa e extensão de maneira satisfatória: $O$ tema 'literatura em sala de aula', já pressupunha que as discussões seriam orientadas para as práticas de ensino; e a dimensão da pesquisa transparece na trajetória dos participantes (de fato, o tema da fala de alguns relacionava-se diretamente a pesquisas de mestrado ou doutorado em andamento ou realizadas). Por último, a extensão foi contemplada pela grande diversidade dos participantes: professores e estudantes de Ensino Médio e Superior oriundos de 16 estados brasileiros. Este último dado também corrobora 0 acerto na estratégia de divulgação do evento, focada nas redes sociais.

Ao abordar a multiplicidade de abordagens do estudo do texto literário em sala de aula na educação básica, foi possível perceber que existe uma carência em discussões desta área, e que futuras ações semelhantes seriam extremamente favoráveis tanto para os docentes quanto para os graduandos (e futuros docentes) da área de Letras.

\section{Referências}

AMÂNCIO, Iris Maria da Costa, GOMES, Nilma Lino e JORGE, Míriam Lúcia dos Santos. Literaturas africanas e afro-brasileira na prática pedagógica. 2 ed. Belo Horizonte: Autêntica, 2014.

BRASIL. Ministério de Educação e Cultura. LDB - Lei $n^{\circ}$ 9394/96, de 20 de dezembro de 1996. Estabelece as diretrizes e bases da Educação Nacional. Brasília: MEC, 1996.

Secretaria de Educação Média e Tecnológica. Parâmetros curriculares nacionais (Ensino Médio)

- Linguagens, Códigos e suas Tecnologias. Brasília, 2000. Disponível em: Acesso em 04 fev. 2020. 
Secretaria de Educação Básica. Ministério da Educação. Orientações Curriculares para o Ensino Médio - Linguagens, códigos e suas tecnologias. Brasília, 2006. Disponível em: Acesso em 15 jan. 2020.

Secretaria da Educação Básica. Ministério da Educação. Orientações Educacionais Complementares aos Parâmetros Curriculares Nacionais. Linguagens, códigos e suas tecnologias.

Brasília. 2002. Disponível em: <http://portal.mec.gov.br/seb/arquivos/pdf/linguagens02.pdf>. Acesso em 02 fev. 2020.

COSSON, Rildo. Letramento literário: teoria e prática. São Paulo: Contexto, 2006.

GRAÚNA, Graça. Contrapontos da literatura indígena contemporânea no Brasil. Belo Horizonte: Mazza Edições, 2013.

ROJO, Roxane. Letramentos múltiplos, escola e inclusão social. São Paulo: Parábola Editorial 2017.

Data de submissão: 25/04/2021. Data de aprovação: 27/10/2021. 